\title{
ECOLOGY AND STATE OF THE ALPINE GRASSLANDS OF WESTLAND
}

\author{
M. J. Wraight \\ Scientific Officer, Forest and Range Experiment \\ Station, N.Z. Forest Service, Rangiora
}

\section{Introduction}

To write of tussock grasslands in Westland may seem a little strange when one usually associates tussock grassland with the mountain ranges, valleys and hills on the eastern side of the main divide. But tussock grasslands above the tree-line probably total $20 \%$ of the area of Westland.

No pastoral use is made of this country. A part from a few unsuccessful attempts to run sheep, both from the West Coast side and the Canterbury side in the 1890 s, nu serious attempt at pastoral occupation has been made. Nevertheless,. these alpine grasslands are of extreme economic importance in watershed protection and they are as vulnerable as the forests to abuse by introduced wild animals.

\section{Types of G rassland Represented}

The following remarks will be confined to the alpine grasslands of the main mountain chain - i.e., those to the east of the Alpine Fault, thus excluding such areas as the tops of the Paparoa and Hohonu Ranges. These abovetimber-line grasslands occur as a belt on the mountain sides from round 3,500 ft to sometimes just over $6,000 \mathrm{ft}$ altitude. At their lower limits, they are free of snow for five to seven months each year. At their upper limits, they are snow-free for about three months. The rainfall is possibly reaching 400in. 'per year. This very high rainfall has two main effects. During the summer, growth conditions are good, but there is an enormous scope for erosion.

The topography is mainly steep to very steep and the soils on such steep slopes and under such heavy rainfalls are shallow, poorly developed, coarse-textured, weakstructured and strongly leached. On the small areas of gentler slopes, alpine_gleys-and-peats-oecur-The-rocks ${ }^{-}$are greywackes with some argillites close to the main divide with a transition to schists towards the west. These are rocks of low erosion resistance.

The grassland types or associations and their habitats have been described in detail for the Hokitika River catch- 
ment (Wraight, 1960). Briefly the pattern is as follows. Immediately above the subalpine scrub where the slopes are gentle (under 30") red tussock (Chionochloa rubra) dominates. In its unaltered state this association provides a very good cover, with tussocks 3 to $4 \mathrm{ft}$ high and deep litter and peat beneath.

Where the slope is steeper, greater than $30^{\prime \prime}$ as it more commonly is, snowgrass, mainly Chionochloa pallens with some C. flavescens, dominates. This association also, in its unaltered state, provides excellent protective cover, with tussocks to $3 \mathrm{ft}$ or more in height, a lower storey of upright growing inter-tussock species, and a reasonable litter layer.

Snowgrass dominates to the point where the snow-free growing season is approximately five months. Further upslope, or in hollows where snow accumulates, and the snow-free period is closer to four months, alpine curly grass (C. crassiuscda) dominates. Although not providing such a tall cover or such deep litter as snowgrass, this association, if unmodified by grazing, can provide good cover with a canopy about 12 in. high and complete ground cover by inter-tussock species and litter.

At higher altitudes still, or where even deeper snow accumulates and the snow-free season is closer to three months, snow-patch grass (C. oreophila) dominates. The tussocks of this grass form a low turf up to 6 in. in height, and with its low growing associated species can give complete ground cover.

On avalanche tracks around the subalpine scrubland and even down into the forest, "avalanche-grass" (Poa cockayniana) dominates. This grass, which looks like a very lax and floppy silver-tussock (P. caespitosa) is well adapted to being over-run by avalanches. Good growth conditions prevail on the young soil of the avalanche debris and the altitude is moderate only so that, following avalanches, a complete cover is soon restored. The association is seral, tending always to return to forest, subalpine scrub, or snowgrass dominated grassland.

In contrast to the drier mountains on the eastern side of the main divide there is little development of fellfield above the $\mathbf{C}$. oreophila grassland.

This pattern, as found in the Hokitika River catchment, applies-as-far-as-is-knownthrougnoucthe rest of Westland except that, north of the Taramakau River, carpet grass (C. australis) occurs. This species, where it occurs, dominates above the snowgrass zone, perhaps sharing some of the C. crassiuscula and C. oreophila habitat. The dense 6 in. 
deep carpet it provides is an extremely effective cover for watershed protection.

In their original condition, these alpine grasslands were able to stand up to the local conditions of extremely high rainfall, steep to very steep topography, and poorly developed soils from erosion-prone rock. As stated earlier, there has been negligible grazing of them by sheep or cattle. Fire, likewise, has been of no consequence. The destructive agents have been the introduced mammals - deer, chamois, thar and hares. Over the last 60 years or so, these animals have been very successfully colonizing Westland's mountain region. This colonization is still proceeding. Conditions for the animals have been good. Initially at least there was no shortage of winter browse and shelter and the high rainfalls produced good growth rates of herbage. Further, with no burning, grazing and browsing capacities have been maintained longer to allow higher build-ups in animal numbers. This new animal factor has led steadily towards depletion consequent on both grazing and trampling.

\section{Trends in Depletion}

The snowgrass association is the most widespread of the five main associations. With the longest growing season ( 5 to 7 months), it receives the bulk of the grazing. Stages in deterioration due to grazing are, first, the most palatable upright growing of the inter-tussock species are eliminated and replaced with lower growing ones - e.g., Poa mackayi is replaced by Poa colensoi - and, secondly, the dominant C. pallens is grazed and reduced in size. It is at this stage that the process tends to become irreversible, the depleted sward no longer resisting the high intensity rains on the steep slopes of loose soil. It is at this stage also, that, because of a marked reduction in the snowgrass canopy, survival of snowgrass seedlings becomes difficult because of frost heave. In drier parts of $\mathrm{N}$ ew Zealand, swards depleted to this extent are generally invaded by low-growing unpalatable plants, of at least some soil protection value, but in Westland invasion by these species is prevented. The frequent, prolonged, high intensity rainfalls result in the complete removal of the weakened sward and usually of all the soil. This may happen very suddenly.

In the curly grass (C. crassiuscula) and the snow-patch grass (C. oreophila) associations, the process is essentially similar. There are fewer very palatable plants in the ungrazed swards and the dominants are less relished than 
Alpine Grasslands of Westiand

snowgrass. But the growing season is so much shorter that after any damage the sward is much slower in recovering.

The avalanche-grass ( $P$. cockayniana) association is the most vulnerable to heavy animal use. It contains many palatable plants, and is exposed to further avalanche destruction.

Since it often occurs in tongues extending down into the forest, animals generally make abundant use of it. However, the occasional rocky nature of the terrain may make it less attractive to animals and here, with good growth conditions, recovery from grazing can be rapid.

In both the red tussock (C. rubra) and the carpet grass (c. australis) associations there are very few palatable associated species, the dominants themselves being very low on the palatability scale. Damage is mainly by trampling. This is much more common in the red tussock association since it has a deep peaty topsoil and it is usually found as a narrow band between the subalpine scrub and the snowgrass grassland, thus being exposed to much animal traffic. Large areas of carpet grass away from travelling routes are often relatively undamaged.

Superimposed upon these effects of grazing on the different associations are the effects of rock type. In general, the effects of grazing are much more serious on greywacke than on schist. In the process of erosion, greywacke breaks into blocks of a cuboid nature, readily forming screes. Schist, on the other hand, although weathering faster, breaks down into plates rather than chunks. Scree formation rarely occurs and, with fast weathering, a new soil of "reasonable" fertility is produced.

What of the future? Without the alpine grasslands of Westland in a healthy condition, flood protection work on the fertile flood plains is going to be very costly. At present, without any economic means of artificial re-vegetation available, the one thing that can be done is to attempt to remove the causal agents of deterioration, the deer, chamois, thar and hares. By doing this an opportunity can be provided for moderately deteriorated swards to recover and for deterioration to be halted in the relatively untouched swards.

Will an all-out effort to redıre animal numbers be worth while? During the summer of 195738, a survey was made of the condition of the forests, subalpine scrubland and alpine grasslands of the Hokitika River catchment ( Wraight, 1960). Permanent plots were established throughout the catchment to measure any changes in condition. 
The animal control programme which had started just before this original survey was increased in intensity over the next six years. The plots were remeasured during the summer 1963-64. Results are encouraging. Though evaluation of plot data is not yet completed, it is apparent that no plots show any marked deterioration over the six-year interval, most show some improvement in condition, and a few indicate spectacular recovery. This was better than had been anticipated and it seems that the high rainfall, despite its significance in causing spectacular erosion, is also responsible for the good growth conditions which allow rapid recovery. There is certainly no evidence of such a potential for rapid recovery in damaged alpine grasslands anywhere else in New Zealand.

\section{REFERENCE}

Wraight, M. J., 1960: The alpine grasslands of the Hokitika River catchment, Westland. N.Z. J.Sci., 3: 306-32. 